\title{
Respiratory System Findings Original Result
}

National Cancer Institute

\section{Source}

National Cancer Institute. Respiratory System Findings Original Result. NCI Thesaurus. Code C123984.

The outcome of the respiratory system assessment as orig inally received or collected. 